\title{
DEBATE
}

\section{Low levels of persistent organic pollutants raise concerns for future generations}

\section{G M Solomon, A M Huddle}

J Epidemiol Community Health 2002;56:826-827

Bans and regulation in many countries have reduced the environmental levels of many persistent organic pollutants (POPs). Despite these declines, there is still evidence of exposures in a range associated with adverse health effects. This seeming paradox is a result of the realisation that levels once presumed safe can cause subtle but important health effects. For example, levels of PCBs now shown to affect human brain development are nearly one million-fold lower than levels previously believed safe. These findings add urgency to efforts to globally eliminate these chemicals, and carry lessons for persistent pollutants that are still in widespread use today, such as the polybrominated diphenyl ethers (PBDEs) and synthetic musks.

See end of article for authors' affiliations

Correspondence to Gina M Solomon, Natural Resources Defense Council, 71 Stevenson Street, Suite 1825, San Francisco, CA 94105, USA;

gsolomon@nrdc.org chafer and Kegley show that persistent organic pollutants (POPs) banned in the United States decades ago are still a problem in the nation's food supply. ${ }^{1}$ Others, however, have pointed out that bans and strict regulation of many POPs are clearly associated with decreasing concentrations of these chemicals in breast milk samples in many parts of the world (see fig l). ${ }^{2}$ It initially seems a paradox that dramatic decreases in these contaminants have not eliminated the spectre of adverse health effects. The roots of this paradox are worth exploring because they offer historical lessons that we would do well to learn.

Although the POPs have a range of toxic properties, there is a recurrent historical pattern that characterises the science around many of these chemicals. In the example of the polychlorinated biphenyls (PCBs), initial small studies in adult male workers, exposed at high levels, did not demonstrate many dramatic health effects. Poisoning was associated with an acne-like syndrome, and some liver function abnormalities were noted, but the chemicals were initially touted as relatively non-toxic. ${ }^{3}$ Because of the apparent low toxicity, the fact that these chemicals were persistent and accumulated in fat was not considered of great concern. Few people at the time heeded Rachel Carson's admonition that: "This pollution is for the most part irrecoverable; the chain of evil it initiates ... is for the most part irreversible." ${ }^{\prime 4}$ The initial negative studies on PCBs are a reminder of the importance of studying the right effects, in the right age group, at the right time. In fact, the major concerns now associated with PCBs are neurotoxic, anti-thyroid, and immunotoxic effects from exposure during the prenatal period. ${ }^{5}$ It is no surprise, in retrospect, that the early studies of adult workers would not have been adequate to detect these effects.

Early animal studies investigating the toxicity of the PCBs to the developing fetus were also of little help in fully predicting the scale of the hazard. ${ }^{6}$ In the 1970s, the initial toxicology studies revealed an apparent "no observable adverse effect level" (NOAEL) based on the most sensitive end point examined at the time: fetal toxicity in the rodent at a level of $20-26 \mathrm{mg} / \mathrm{kg} /$ day. ${ }^{6}$ Subsequent study revealed neurobehavioural abnormalities in the rat at exposures an order of magnitude lower than those causing overt toxic effects in the fetus-at $0.2-2 \mathrm{mg} / \mathrm{kg} /$ day. $^{6}$ In the monkey, effects on learning and behaviour occur with exposures over a hundred times lower than those that cause significant effects in the rat. Finally, human epidemiological studies of children exposed to PCBs prenatally have revealed neurological effects such as decreased IQ, poorer performance on neurobehavioural tests, and delayed reading ability at levels about a thousand times lower than those that cause detectable impairment in monkeys. ${ }^{7}$ The NOAEL in humans is now estimated to be about $0.0001 \mathrm{mg} / \mathrm{kg} / \mathrm{day}$. The levels currently known to cause impairment in the human fetus are about a million times lower than the levels initially thought to be a concern based on toxicity to the fetus in the rat.

PCBs are not the only persistent pollutants showing an historical pattern of toxicity at lower and lower doses as studies gradually hone in on the relevant health effects and populations at risk. The nearly 20 year saga of the US Environmental Protection Agency (EPA) reassessment of dioxin repeats the same messages. Over time, the levels of concern became ever lower until finally EPA admitted that there was no apparent threshold for even the non-cancer effects of dioxin, with risks at every exposure level, even below the range of prevalent exposures in our society today. In the case of dieldrin, recent major cohort studies on breast cancer in Denmark have revealed links between increased risk of breast cancer and dieldrin residues in a woman's fat. ${ }^{8}$ Women with slightly higher levels of dieldrin in their fat who do get breast cancer are also at higher risk of having a more aggressive tumour and of dying from the disease. 9 These relatively new research findings come far too late to prevent the widespread exposure to dieldrin that exists today.

Abbreviations: POPs, persistent organic pollutants, PBDEs, polybrominated diphenyl ethers; PCBs, polychlorinated biphenyls 


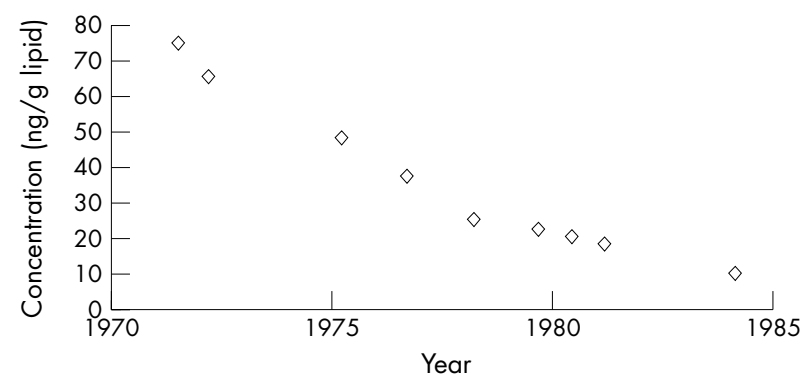

Figure 1 Dieldrin in breast milk, Sweden.



Figure 2 Polybrominated diphenyl ethers (PBDEs) in breast milk, Sweden.

The history of ever lower levels of concern for many persistent toxic chemicals has created a compelling case for prevention. Many scientists and advocates have pointed out that waiting for clear evidence of harm in human populations is tantamount to closing the proverbial barn door long after the animals have scattered far and wide. If we fail to identify chemicals in use today that are likely to be the PCBs, dioxins, and dieldrins of the future, then future generations may be faced with evidence that the nutritious food they eat may be tainted by health risks.

Some current examples that demand our immediate attention include the brominated flame retardants and the synthetic musks. The polybrominated diphenyl ethers (PBDEs) are used as flame retardants in plastics, polyurethane foams, and textiles. Global production of these chemicals is approximately 40000 tons per year. The chemical structure of the PBDEs is similar to the non-coplanar PCBs. The PBDEs are environmentally persistent and bioaccumulate rapidly. Levels of the PBDEs have doubled every five years in breast milk samples from Sweden (see fig 2), and residues of these chemicals have been detected globally including in the Arctic, where they have never been used..$^{10}$ The toxicological evidence so far strongly suggests that the PBDEs are thyroid hormone disruptors, that they are neurotoxic to the developing brain, and that they may have immunotoxic properties similar to the PCBs. ${ }^{11}$

The synthetic musks (including the nitro musks and polycyclic musks) are also in widespread use as fragrances in personal care products and cleaning products. They are produced at over 7000 tons per year. ${ }^{12}$ Although there is little information on health effects from these chemicals, they are environmentally persistent, have been detected in sediment and fish samples from many regions, and have been reported in human blood and breast milk samples. ${ }^{13}{ }^{14}$ There is no question that it will take years for adequate prospective epidemiological studies to investigate whether these new POPs are causing health effects in humans. Meanwhile, if there is no regulatory action, the levels of these chemicals will continue to increase in the environment, in our food supply, and in maternal milk.

It is time to take a positive lesson from chemicals such as the PCBs, DDT, and dieldrin: although they do persist in the environment, bans and strict regulation have resulted in clearly quantifiable decreases in human exposure over time. Instead of expending our efforts debating the exact risks from banned chemicals in the US food supply today, we should direct our efforts toward eliminating all chemicals that are persistent, lipophilic, and bioaccumulative from production worldwide.

Authors' affiliations

G M Solomon, Natural Resources Defense Council, San Francisco, California, USA

A M Huddle, Strybing Arboretum Society, San Francisco, California, USA

\section{REFERENCES}

1 Schafer KS, Kegley SE. Persistent toxic chemicals in the US food supply. J Epidemiol Community Health 2002;56:813-17.

2 Solomon GM, Weiss PM. Chemical contaminants in breast milk: time trends and regional variability. Environ Health Perspect 2002;110:A339-47

3 Ouw HK, Simpson GR, Siyali DS. Use and health effects of Aroclor 1242, a polychlorinated biphenyl, in an electrical industry. Arch Environ Health 1976;31:189-94.

4 Carson R. Silent spring. Boston: Houghton Mifflin, 1962:6.

5 Birnbaum L. Developmental effects of dioxins and related endocrine disrupting chemicals. Toxicol Lett 1995;82/83:743-50.

6 Tilson HA, Jacobson JL, Rogan WJ. Polychlorinated biphenyls and the developing nervous system: Cross-species comparisons. Neurotoxicol Teratol 1990; 12:239-48.

7 Jacobson JL, Jacobson SW. Effects of in utero exposure to PCBs and related contaminants on cognitive functioning in young children. J Pediatr 1990; 1 16:38-45

8 Hoyer AP, Grandjean P, Jorgensen T, et al. Organochlorine exposure and risk of breast cancer. Lancet 1998;352:1816-20.

9 Hoyer AP, Jorgensen T, Brock JW, et al. Organochlorine exposure and breast cancer survival. J Clin Epidemiol 2000;53:323-30.

10 Ikonomou M, Rayne S, Addison R. Exponential increases of brominated flame retardants, polybrominated diphenyl ethers, in the Canadian Arctic from 1981 to 2000. Environ Sci Technol 2002;36:1886-92.

11 Eriksson P, Jakobsson E, Fredriksson A. Brominated flame retardants: a novel class of developmental neurotoxicants in our environment? Environ Health Perspect 2001;109:903-8.

12 Lyons G, Linley-Adams G. Synthetic musk fragrances. WWF Briefing, 2000. (http://www.ngo.grida.no/wwfneap/Publication/briefings/ Musk.pdf)

13 Kafferlein HU, Angerer J. Trends in the musk xylene concentrations in plasma samples from the general population from 1992/1993 to 1998 and the relevance of dermal uptake. Int Arch Occup Environ Health $2001 ; 74: 470-6$.

14 Rimkus G, Rimkus B, Wolf $M$. Nitro musks in human adipose tissue and breast milk. Chemosphere 1994;28:421-33. 